\title{
Cervical Cancer Knowledge,Screening Service Utilization and Predictors of Precancerous Cervical Changes: A Population Based Survey of Sexually Active Women in Lagos, South Western Nigeria
}

\author{
Olawunmi O. Adeoye ${ }^{\star 1,2}$, Olufunmi Fawole ${ }^{3,2}$, Ike Ajayi ${ }^{3}$ and Patrick Nguku² \\ ${ }^{1}$ University College Hospital, Ibadan, Nigeria; ${ }^{2}$ Nigeria Field Epidemiology and Laboratory Training Programme, Abuja, Nigeria; \\ ${ }^{3}$ Department of Epidmiology and Medical Statistics, UCH, Ibadan, Nigeria
}

\section{Objective}

This study set out to determine the knowledge of cervical cancer, utilization of cervical cancer screening services and predictors of precancerous cervical changes among sexually active women in Lagos, Nigeria.

\section{Introduction}

Cervical cancer is a significant cause of morbidity and mortality among women in developing countries and the second most common cancer in women in Nigeria. Most studies on knowledge of cervical cancer, cervical cancer screening services and precancerous cervical changes in Nigeria are facility based, hence the need for a population based study

\section{Methods}

The study was population based, cross sectional in design. A five stage sampling technique was used to select 332 women from three of the Local Government Areas (LGAs) in Lagos State. Study participants were women above 15 years of age who were sexually active, non-pregnant, and with no previous diagnosis of cervical cancer. A 48 item, interviewer administered semi structured questionnaire was used to collect data.In addition, Visual Inspection with Acetic Acid (VIA) and Visual Inspection with Lugol's Iodine (VILI) were done to detect precancerous changes in the cervix. A precancerous cervical change was defined as having both aceto-whitening on VIA and yellowish changes on VILI. Data were summarized using frequencies and proportions. Chi square and Prevalence Odds Ratio (POR) were used to test for associations. Predictors of developing precancerous cervical changes were determined using logistic regression. Level of significance was set at $5 \%$.

\section{Results}

A total of 350 eligible women were recruited but 332 consented, giving a response rate of $95 \%$. The mean age of respondents' mean age was 39.0 years ${ }_{+}+10$. Most were married $(227 ; 68.6 \%)$. Only (135) $41.9 \%$ of respondents were aware of cervical cancer, $32.3 \%$ of whom had good knowledge of the disease. The mass media and health workers were the most common sources of information $(65.9 \%$ and $24.4 \%$ respectively). Only $11(3.3 \%$ ) of respondents had ever had a cervical cancer screening done and none had ever had neither Human Papilloma Virus (HPV) DNA screening nor HPV vaccine. Respondents with no education/low education level were four times less likely to have a good knowledge of the disease compared with those with high education(having a tertiary level of education). [POR 0.24 (95\% CI; 0.08-0.68). A significantly higher proportion of those with a good knowledge $(9 ; 40.9 \%)$ of cervical cancer compared with those with poor knowledge $(2 ; 2.3 \%)$ had had at least one screening either by Pap smear or VIA/VILI done in their lifetime $(p=<0.001)$. Most of the reasons given for never to have been screened for cervical cancer were belief that screening is not important $(15 ; 31.3 \%)$ and non availability of screening facility $(15 ; 31.3 \%)$. Thirteen percent (43) had Precancerous cervical changes. Multiparity [POR4.27(95\% CI: 1.95-9.39)], early coitache [POR $15.72(95 \%$ CI: 7.52- 32.83)], multiple sexual partnering [POR 18.68(95\% CI: 8.76-39.84)] and multiple risks [POR 14.46(95\% CI: 6.53- 32.03)] were associated with precancerous cervical changes. However, on logistic regression, only multiple sexual partnering and early coitache predicted having precancerous cervical changes[AOR 9.69(95\% CI 3.29- 28.50) and [AOR 7.93(95\% CI 3.20-19.6) respectively].

\section{Conclusions}

There was poor knowledge and low utilization of cervical cancer screening services. The study also shows a predictive relationship between multiple sexual partnering, early coitache and having precancerous cervical changes. Culturally sensitive health education programmes on safe sexual practices and benefit of screening for cervical cancer with special target of women with early coitache and multiple sexual partners was commenced in the area and is still continuing.

\section{Keywords}

Cervical cancer; knowledge; utilization; Lagos; Precancerous cervical changes

\section{References}

1. Ajayi I, Adewole I. Knowledge and Attitude of General Outpatient Attendants in Nigeria to Cervical Cancer. Cent Afr J Med.1998 Feb;44(2):41-3.

2. IARC GLOBOCAN. IARC Handbooks of Cancers Prevention. Cervix Cancer Screening. Lyon, France: International Agency Research on Cancer. 2008.

3. Thomas J. O., Ojemakinde K. O., Ajayi I. O., Omigbodun A. O., Fawole O. I. \& Oladepo O.. Population-Based Prevalence of Abnormal Cervical Cytology Findings and Local Risk Factors in Ibadan, Nigeria: Implications for Cervical Cancer Control Programs and Human Papilloma Virus Immunization. Acta Cytol .2012. 56, 251-8.

\author{
*Olawunmi O. Adeoye \\ E-mail: wunmiolat@yahoo.com
}

